\title{
The Construction of Apparel Brand Value Perception Based on Grounded Theory: A Case Study of the Intellectual 80's Women in Hangzhou
}

\author{
Xiangyang Bian ${ }^{1}$, Yiling Zhang ${ }^{1,2} \&$ Ziying $\mathrm{Yu}^{2}$ \\ ${ }^{1}$ College of Fashion and Design, Donghua University, Shanghai, China \\ ${ }^{2}$ Applied Technical School, Jiaxing University, Jiaxing, China \\ Correspondence: Xiangyang Bian, College of Fashion and Design, Donghua University, Shanghai, No. 1882, \\ West Yan-an Road, 200051, China. Tel: 86-21-6237-3978. E-mail: bianxy@dhu.edu.cn
}

Received: June 22, 2018 Accepted: July 30, $2018 \quad$ Online Published: August 31, 2018

doi:10.5539/ass.v14n9p83

URL: https://doi.org/10.5539/ass.v14n9p83

\begin{abstract}
In terms of the theoretical vacancy of apparel brand perceived value, this paper explores the dimensions of perceived value of apparel brand from the perspective of consumers. With lessons from grounded theory, one can build initial model of apparel brand value system through depth interviews, substantial coding, and theoretical saturation detection. Then, by means of quantitative empirical research, the logical relationship between factors can be investigated via factor analysis and independent test. The results show that the perceived value theory conclude two dimensions namely the perceived benefits and perceived costs. The perceived benefits includes functional value, social value, emotional value, cognitive value, experience value. Perceived costs includes purchase costs \& risks and the use cost. It also fully demonstrates the relative importance in perceiving various dimensions of apparel brand for the intellectual 80's women in Hangzhou.
\end{abstract}

Keywords: grounded theory, perceived value, perceived benefit, perceived cost, apparel brand

With the rapid development of information technology, the globalization process is irresistible, making the consumer oriented retail market more complex and changeable. The apparel market also develops from traditional price competition, quality competition and scale competition to the brand competition. It not only brings the opportunity to the garment enterprises, but also brings challenge. The apparel enterprises are increasingly aware that only in depth understanding of the consumer demand and decision-making process can create a competitive brand; They also realize that only by constantly improving brand value can keep garment enterprises alive in fierce competition. Therefore, the research of brand value enhancement has gradually become the research hot spot of clothing social psychology and marketing. Perceived value, as a measure of consumers' "gain" and "loss" of brands, is an essential consideration in brand strategy performance appraisal. And it is thus clear that reasonable value construction and brand operation through functional value and non functional value is an effective way to enhance the competitiveness of apparel brand. Therefore, enhancing the perceived value of consumers is the industry demand and trend, and it is the strategic goal of the transformation and upgrading of the apparel brand.

\section{Perceived Value and Research Review}

In 1990s, Keller put forward the brand value based on customers. That is, the Customer Perceived Value (CPV), which refers to the overall evaluation of the product or service utility after the trade-off between the perceived benefits of consumers and the cost of product or service. It is the subjective cognition of consumers to value of products or services. The subjective cognition of value is different from the objective value, which is also a common point of view in the academic world. Since then, there has been a lot of research on brand value from the perspective of customers. However, due to the subjectivity and dynamics of consumer perceived value, the similarity of "perceived value" proposed by scholars is not the same. Most scholars believe that perceived value has three aspects as following: (1) Consumer perceived value is acquired by customers rather than products or services. (2) The perceived value is determined by the perception of consumers, not the imagination or desire of the enterprise (Khalifa, 2004). (3) Perceived value can influence consumers' purchase intention to a certain extent. 
In the development of customer value theory, the study of perceived value mainly focuses on two aspects: On the one hand, it is the research on the composition of consumer value, mainly based on quantitative statistics and model construction. Sheth, Newman \& Gross (1991) and Pet-rick (2002) are the representative studies of the perceived value dimension. They analyze the "profit and loss" of the perceived products from the customers, and provide a perfect measurement scale for the subsequent empirical research on perceived value. On the other hand, it is a study of the related variables of perceived value. Recently, many studies like Monroe et al. (1985)have done empirical research on it. At the same time, with the deepening of the study of perceived value abroad, many scholars in China also focus their attention on it. However, the research on perceived value in China is still in the initial stage, which is based on the western theory and mainly based on the concept research, and a small amount of empirical research which combines the national conditions. Ye Zhigui (2003) carefully studied the relationship between perceived value hierarchy, dynamism and individuality in his article. Ge Xiao (2005) uses the value model of Sheth, it covers five kinds of consumer values, such as practical value, social value, emotional value, taste value and conditional value. It divides Chinese consumers into three groups to analyze. He Jun (2006) studies the perceived value of cosmetics brand through exploratory factor analysis in the research of its evidence. In addition to the functional value, social value and emotional value, it obtains two new dimensions of green value and perceived cost. Cang Ping and Cai Wen (2008) use structural equation to verify the intrinsic relationship between various indicators in brand equity.

\section{Research on the Quality of Apparel Brand Value Perception}

\subsection{Research Program}

In qualitative studies, Grounded Theory is regarded as a comparative scientific and effective research method by the international mainstream academia, which is first proposed by Barney Glaser \& Anselm Strauss (1967). This method has been widely applied in the fields of sociology, pedagogy, religion, management and so on. The research method is a qualitative research without any presuppositions. At present, there is no mature theoretical research on the key influencing factors of apparel brand perception value and their internal mechanism. This paper selects the intellectual 80's women in Hangzhou as the investigation object and uses the method of Grounded Theory to explore the group's perception factors of apparel brand value. In the base of literature review, deep interview and focus group, this paper analyzes the perceived value elements and inner relationship between them, and finally forms the perceived value system of apparel brand. In addition to consumers, the interviewees also have experts in the garment industry and enterprises. The interview content is rooted in the "elements of brand perceived value", so as to get first-hand sample information. The following figure is the step of qualitative research using grounded theory in this study.

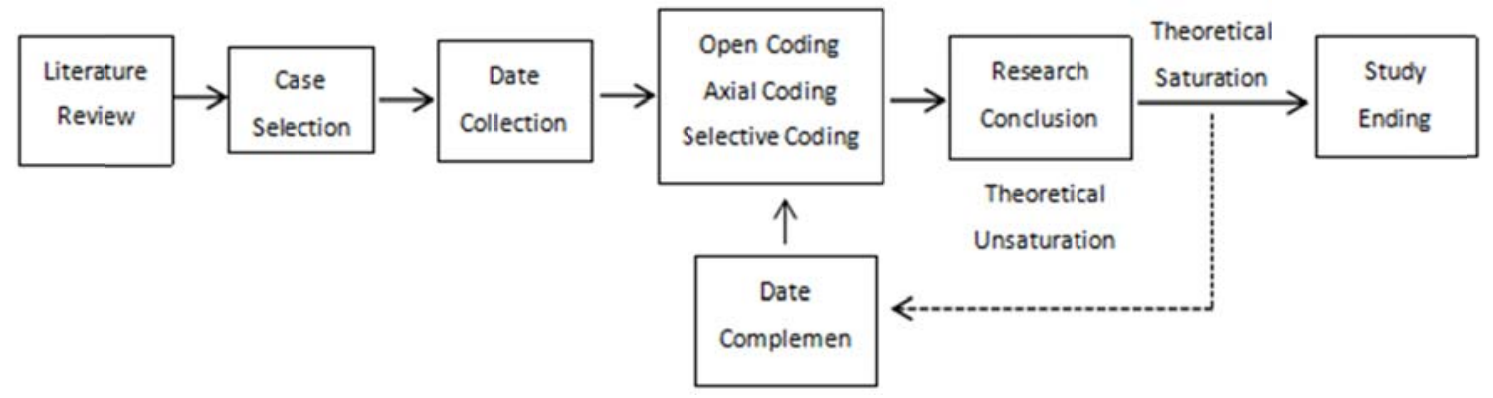

Figure 1. Process Diagram of Grounded Theory

\subsection{Data Collection and Coding}

In this study, depth interviews and focus group were used to investigate the intellectual 80's women in Hangzhou. The entire interview lasted for nearly 4 months, and obtained 221 interviews data. Then, 112 representative interviews were selected for data coding and analysis, and the remaining 30 interviewed and 11 experts were used to theoretical saturation test.

After the interview, a number of items are obtained by NVIVO11.0. Considering the research materials of brand perceived value and the description of the elements' characteristics, this study combines the duplicate or similar items of the semantic expression, and selects the senior scholars and experts of apparel brand management to discuss and classify the items. Finally, 30 initial concepts and 18 categories are extracted from the data, and these items form the system of apparel brand perceived value. After that, the 18 categories of open coding are classified and logically analyzed, then the 7 main categories of functional value, social value, emotional value, cognitive value, experience value, cost of payment and cost of use were offered. The connotation of each main 
category and its corresponding theoretical coding are shown in Table 1. During the interview, I found that the consumer in the actual brand adoption behavior, the main categories have different contributions, because of the situation or motivation different. It may only be influenced by one value of the perceived value, but in most cases it is the result of more than two value interactions.

Table 1. The main categories of perceived value of apparel brand

\begin{tabular}{|c|c|c|c|}
\hline Categories & Main category & $\begin{array}{l}\text { Corresponding } \\
\text { category }\end{array}$ & Category connotation \\
\hline \multirow{14}{*}{$\begin{array}{l}\text { Perceived } \\
\text { benefit }\end{array}$} & \multirow{3}{*}{$\begin{array}{l}\text { Functional } \\
\text { value }\end{array}$} & Quality & The quality of brand clothing is always reliable. \\
\hline & & Comfort & Brand clothing is comfortable, fit, and good effect. \\
\hline & & Appearance & $\begin{array}{l}\text { The overall design of brand clothing conforms to the aesthetic } \\
\text { standard. }\end{array}$ \\
\hline & \multirow{4}{*}{$\begin{array}{l}\text { Social } \\
\text { value }\end{array}$} & Self-expression & Can highlight my status, personality and taste. \\
\hline & & Social identity & Can get the approval of others. \\
\hline & & $\begin{array}{l}\text { Situational } \\
\text { property }\end{array}$ & Suitable for wearing brand clothing to attend some public occasions. \\
\hline & & Cultural property & Brand can convey specific cultural connotations. \\
\hline & \multirow{2}{*}{$\begin{array}{l}\text { Emotional } \\
\text { value }\end{array}$} & Preference & Like to buy brand clothing. \\
\hline & & Trust & Brand clothing is trustworthy. \\
\hline & \multirow{3}{*}{$\begin{array}{l}\text { Cognitive } \\
\text { value }\end{array}$} & Novelty & Brand novelty, including clothing, service, image, etc. \\
\hline & & Fashionable & Brand clothing is in line with fashion. \\
\hline & & Unique & Brand has distinctive features. \\
\hline & \multirow{2}{*}{$\begin{array}{l}\text { Experience } \\
\text { value }\end{array}$} & Service property & Service provided by the brand. \\
\hline & & Desirable & $\begin{array}{l}\text { Brand clothing meets my expectations in terms of quality, culture, } \\
\text { personality, and so on. }\end{array}$ \\
\hline \multirow{4}{*}{$\begin{array}{l}\text { Perceived } \\
\text { cost }\end{array}$} & \multirow{3}{*}{$\begin{array}{c}\text { Cost of } \\
\text { payment }\end{array}$} & Monetary cost & The money cost of buying brand clothing. \\
\hline & & Risk cost & Risk cost of buying brand clothing. \\
\hline & & Convenience & $\begin{array}{l}\text { The convenience of buying brand clothing, such as transportation, } \\
\text { payment, and so on. }\end{array}$ \\
\hline & Cost of use & Maintenance cost & $\begin{array}{l}\text { Loss of time, energy and money caused by unmanageable } \\
\text { conditions. }\end{array}$ \\
\hline
\end{tabular}

\section{Quantitative Analysis of Apparel Brand Value Perception}

\subsection{Research Program}

After the qualitative research has drawn the main categories of apparel brand perception value, the initial model of brand perception value is established, and the quantitative analysis is carried out to clarify the relative importance of the variables. The scale used in quantitative research is on the basis of the maturity scale of domestic and foreign scholars' literature, and combined with the adjustment of apparel brand characteristics. So the specific items of the seven main categories in the initial model are determined, and the initial questionnaire is formed. In the design of the scale, we mainly refer to the perceived value theory of Sheth. (1991), Zeithaml et al. (2000), Sweeney \& Sou tar (2001), the customer experience theory of Sch mitt, and the perceived risk theory of Strader \& Shaw. The measurement scales of these scholars are already mature, and have been verified by many other researchers. However, because this research object is different from the traditional product or service, it requires the author to re-examine the dimensions of perceived value. Therefore, in the design of each dimension scale, it takes into account the popularity of clothing, apparel brand characteristics, and the service experience. Based on the initial scale, this paper makes some supplements and modifications to the items. In order to ensure the reliability and validity of the research scale, a revised questionnaire was formed after a small sample survey and four measurement terms (F25, F27, F29 and F44) with low correlation were eliminated. And the revised measurement indexes are shown in Table 2. 
Table 2. Revised perceived value measurement scale

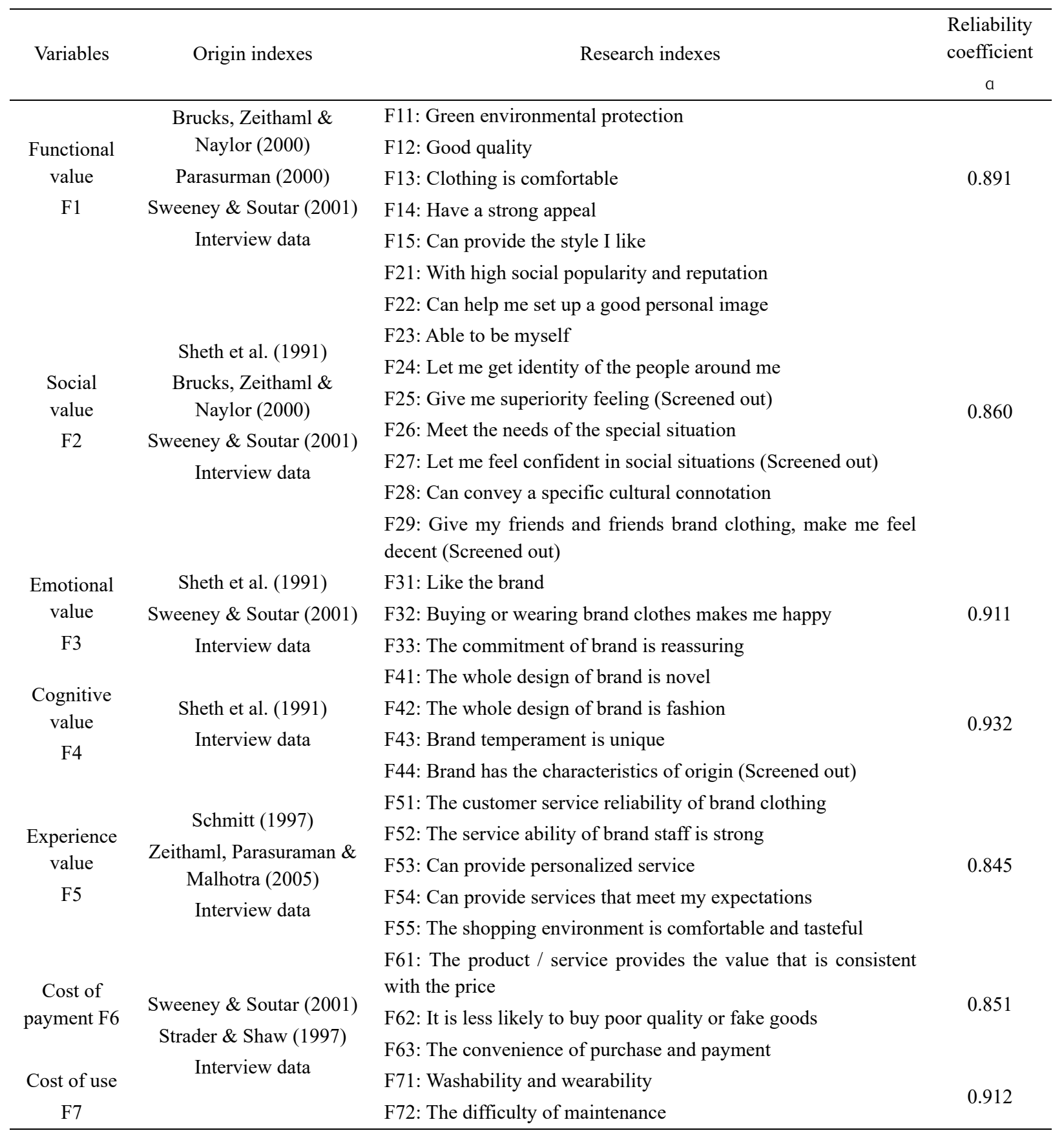

\subsection{Data Statistics and Analysis}

The formal questionnaire is divided into two parts: the first part is the individual basic information; the second part is the measurement of apparel brand perception value. Based on two main axes of perceived benefit and perceived cost, this survey measures the importance of each dimension of apparel brand value. For the importance of the indexes, we use 7-Likert scale to measure. The higher the score is, the more reasonable the evaluation index is. The subjects mainly focus on the intellectual 80 's women, because " 80 's" has become one of the main groups of clothing consumption. Most of them have high literacy, high education, and have a high position in the society. They pay more attention to the culture and symbolic meaning of the brand compared with other women. The questionnaire survey lasted for 3 months, and a total of 563 questionnaires were collected. After screening, 540 effective questionnaires were selected, and the efficiency of the questionnaire recovery was 95.91\%. The basic information of the respondents: The educational level of undergraduate, master, doctor and above accounted for $58.9 \%, 35.63 \%$ and $5.48 \%$ of the total respectively; And the occupations of students in 
school, institutions, enterprise white-collar workers, private owners and freelancers for 1.37\%, 27.4\%, 49.32\%, $13.70 \%$ and $88.22 \%$ respectively; The monthly income is mainly concentrated in $8000-12000$ yuan and $12000-20000$ yuan, accounted for $44.52 \%$ and $34.19 \%$ of the total respectively; The average price of single item clothing is $200-500$ yuan, accounting for $50.68 \%$ of the total survey.

According to the statistics of SPSS19.0, the results show that the Cronbach's a coefficients of functional value, social value, emotional value, cognitive value and experience value are $0.891,0.860,0.911,0.932,0.845$ respectively, and the Cronbach's a coefficients of perceived cost of purchase and use are $0.851,0.912$. The Cronbach's a coefficients of all dimensions are more than 0.7 , and the Cronbach's a coefficients of the total scale is 0.939 , the reliability is higher, and the structure of the scale is reasonable. It is a credible and effective measuring tool. The reliability of the scale is high, reflecting the scale is reasonable. So it's a credible and effective measurement tool.

Table 3. Test of KMO and Bartlett

\begin{tabular}{lcc}
\hline \multicolumn{2}{c}{ Kaiser-Meyer-Olkin Measure of Sampling Adequacy } & .729 \\
\hline & The approximate chi-square value & 3012.431 \\
Bartlett's Test of Sphericity & df & 1225 \\
& Sig. & .000 \\
\hline
\end{tabular}

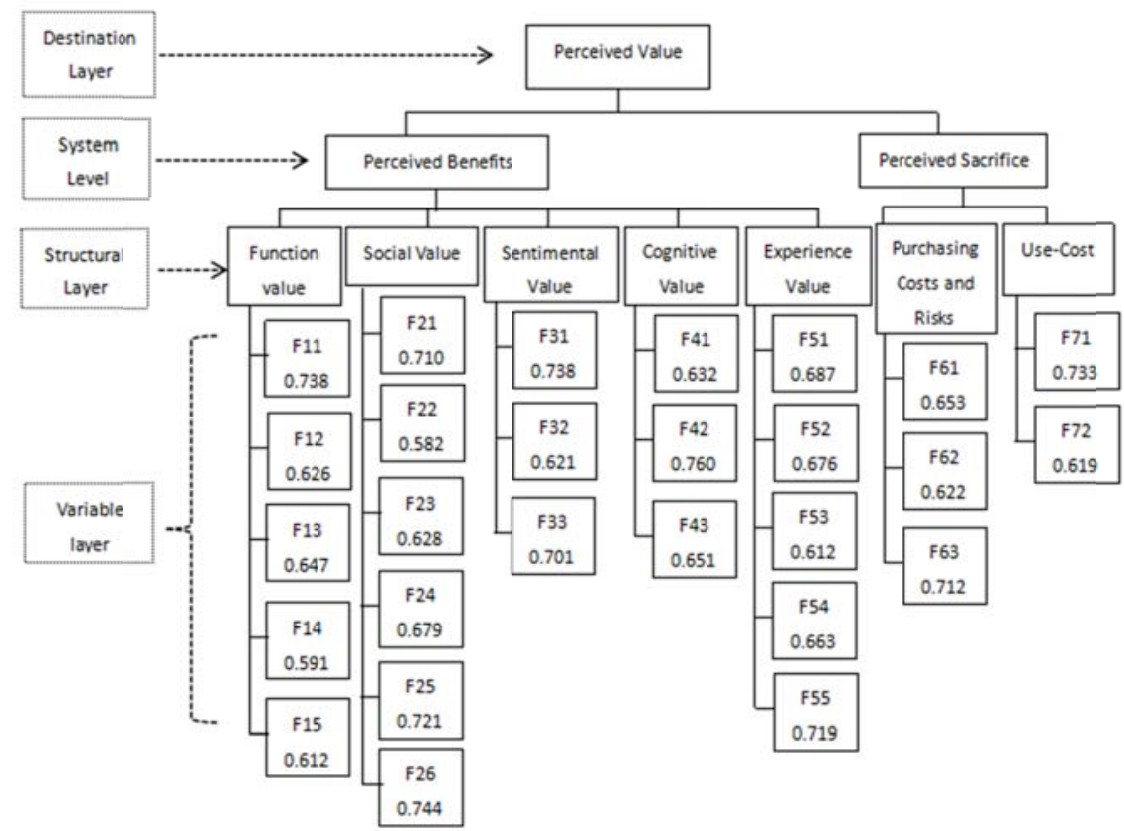

Figure 2. The construction of apparel brand value perception

At the same time, KMO sample measures and Bartlett ball test (Table 3) were performed on the samples obtained. It shows that the KMO was 0.729, far greater than 0.50, and according to Bartlett spherical test (sig), the $\mathrm{P}$ value is 0 , less than 0.05 , indicating that there is a strong correlation between the variables, so the data was suitable for factor analysis. On the basis of the suitability test of factor analysis, the principal component method is used to extract factors. The principle of factor extraction is that the eigenvalue is greater than one. Using the maximum variance rotation method, the maximum number of iterations is 25 . The posterior matrix of factor analysis shows that the result of factor extraction is consistent with the dimension of apparel brand perceived value in the original scale. The eigenvalues of each factor were 2.158, 2.142, 1.985, 1.670, 2.118, 2.335 and 1.149 , which were greater than one, and the cumulative variance is $88.431 \%$, indicating that the interpretation of apparel brand perceived value reached an acceptable level by those seven factors. Then, according to the factor loading of perceived value, the perception value system of apparel brand is obtained (Figure 2), which shows the relative importance of each variable on the factor.

\subsection{The Relative Importance of Brand Value Perception Elements}

The importance of the index is expressed by 7-Likert scale. The scale is divided into 1 to 7 levels. The higher the score is, the more reasonable the evaluation index is. Consumers' attention to each dimension can be judged by 
comparing $\mathrm{P}(\mathrm{Fi}>4)$. That is, the respondents who choose more than $4(5,6,7)$ think the index is important, and the greater the $\mathrm{P}(\mathrm{Fi}>4)$, the more important the $\mathrm{Fi}$ is.

According to the factor analysis, the factor score coefficient of Fi and the corresponding explanatory variable is obtained, and then the factor score is calculated through the factor score function. In the formula, Fi is the factor and Fxy is the explanatory variable corresponding to each factor.

$\mathrm{F}_{1}=0.211 \mathrm{~F}_{11}+0.198 \mathrm{~F}_{12}+0.172 \mathrm{~F}_{13}+0.209 \mathrm{~F}_{14}+0.223 \mathrm{~F}_{15}$

$\mathrm{F}_{2}=0.160 \mathrm{~F}_{21}+0.172 \mathrm{~F}_{22}+0.155 \mathrm{~F}_{23}+0.159 \mathrm{~F}_{24}+0.168 \mathrm{~F}_{25}+0.176 \mathrm{~F}_{26}$

$\mathrm{F}_{3}=0.335 \mathrm{~F}_{31}+0.342 \mathrm{~F}_{32}+0.287 \mathrm{~F}_{33}$

$\mathrm{F}_{4}=0.351 \mathrm{~F}_{41}+0.299 \mathrm{~F}_{42}+0.328 \mathrm{~F}_{43}$

$\mathrm{F}_{5}=0.172 \mathrm{~F}_{51}+0.196 \mathrm{~F}_{52}+0.201 \mathrm{~F}_{53}+0.213 \mathrm{~F}_{54}+0.219 \mathrm{~F}_{55}$

$\mathrm{F}_{6}=0.317 \mathrm{~F}_{61}+0.301 \mathrm{~F}_{62}+0.342 \mathrm{~F}_{63}$

$\mathrm{F}_{7}=0.490 \mathrm{~F}_{71}+0.0 .506 \mathrm{~F}_{72}$

Table 4. Statistics of $\mathrm{Fi}>4$

\begin{tabular}{cccccccc}
\hline & $\mathrm{F}_{1}$ & $\mathrm{~F}_{2}$ & $\mathrm{~F}_{3}$ & $\mathrm{~F}_{4}$ & $\mathrm{~F}_{5}$ & $\mathrm{~F}_{6}$ & $\mathrm{~F}_{7}$ \\
\hline Mean & 5.1971 & 4.6210 & 4.0461 & 4.5168 & 4.325 & 4.4108 & 3.8007 \\
SD & 1.3301 & 1.1717 & 2.3050 & 0.9066 & 1.0484 & 0.8740 & 0.5536 \\
Z-Scores & 0.90 & 0.53 & 0.02 & 0.57 & 0.31 & 0.47 & -0.36 \\
$\mathrm{P}$ & 0.8159 & 0.7169 & 0.5080 & 0.7157 & 0.6217 & 0.6808 & 0.3594 \\
\hline
\end{tabular}

The mean value, standard deviation, $\mathrm{Z}$-score $(\mathrm{Fi}>4)$ and probability $\mathrm{P}(\mathrm{Fi}>4)$ of the 540 samples of $\mathrm{Fi}$ are calculated, and the statistical value of Fi is showed in table 4. According to the table 4, the intellectual 80 's women in Hangzhou pay attention to the perceived value of apparel brands is following: functional value (81.59\%), social value (71.69\%), cognitive value (71.57\%), payment cost $(68.08 \%)$, experience value $(62.17 \%)$, emotional value $(50.80 \%)$, and use cost. (35.94\%).

Table 5. Z-scores and probability of $\mathrm{Fi}<5, \mathrm{Fi}>3$ and $3<\mathrm{Fi}<5$

\begin{tabular}{ccccc}
\hline & $\mathbf{F}_{\mathbf{3}}$ & $\mathbf{F}_{\mathbf{5}}$ & $\mathbf{F}_{\mathbf{6}}$ & $\mathbf{F}_{\mathbf{7}}$ \\
\hline $\begin{array}{c}\mathrm{Z}-\mathrm{Scores} \\
(\mathrm{Fi}<5) \\
\mathrm{P}\end{array}$ & 0.41 & 0.64 & 0.67 & 2.16 \\
$(\mathrm{Fi}<5)$ & 0.6591 & 0.7389 & 0.7486 & 0.9846 \\
$\mathrm{Z}-\mathrm{Scores}$ \\
$(\mathrm{Fi}>3)$ \\
$\mathrm{P}$
\end{tabular}

In addition, when the mean value is close to 4, the attitude of the intellectual 80's women in Hangzhou is not clear. According to the results of Table 4, the mean values of F3, F5, F6 and F7 are all close to 4. Therefore, in order to further judge the importance of these 4 variables, we need to calculate the probability that the variables fall between the interval $(3,5)$. Because $\mathrm{P}(3,5)$ represents the probability that the attitude of the respondents to the selected variable is almost indifferent (see Table 5). From table 5, we can see that the probability of Emotional value (F3), Experience value (F5), cost of payment (F6), and cost of use (F7) in the interval $(3,5)$ are great difference. Especially, the probability of Experience value (F5), cost of payment (F6), and cost of use (F7), respectively, $63.51 \%, 69.38 \%$ and $90.97 \%$. That is to say, customers who are not clear about these factors still occupy a large proportion. Therefore, through the management of customer value, we can guide these uncertain customers to develop in favor of enterprises. 


\section{Conclusions and Suggestions}

In the consumer society, clothing consumption not only meets people's physiological needs, but also explains their psychological needs. On the one hand, consumers realize self or pursue individualization by clothing, using brands and products to realize the externalization of self image. On the other hand, they strive to build identity with the help of clothing brands, maintain and strengthen the specific social identity that they identify with, or be separated from a specific group. Through the qualitative research of perceived value dimension and quantitative analysis of evaluation index, we can draw the following conclusions: a) At present, with the continuous promotion of demand, the connotation of clothing brand is constantly enriched. In the consumer's opinion, the brand not only represents the quality of product, it embodies a social status and helps consumers to realize self construction. It can be seen that the brand connotation of consumers covers the spiritual symbols, such as consumption values, life attitude, aesthetic taste, personality cultivation, vogue taste, emotional appeal and so on. Consumer buy a clothing brand not only to consider the function value, but also pays attention to the symbolic value, fashion sense, consumption experience and specific self-expression, as well as the expression of personal feeling. b) The survey group tends to be rational in the clothing brand consumption, they always take all factors into consideration in the decision making. At the same time, the research data show that they pay more attention to the functional value, social value and cognitive value, while the payment cost, consumption experience and emotional value are second, indicating that they are willing to pay for the high cost purchase to be valuable. And they also care about brand consumption experience. c) In addition, there are many respondents in the qualitative research point out that the consistency of brand image and self image also affects their clothing brand consumption, especially in public places, they will consciously or subconsciously link their dress image with scenes, identity, status, taste and personality.

The results of this study can support clothing enterprises to guide consumers' brand decision making by using perceived value. In particular, when the product is homogeneity, the brand is lacking in personality and cultural connotation, only through the targeted positioning, scientific marketing, orderly promotion, effective customer management, the domestic garment enterprises can develop the value of apparel brand and construct a systematic brand system. Only this way can make garment enterprises have a clear meaning of six aspects, such as property, interest, value, culture, personality and users, so as to creating a strong apparel brand.

\section{Acknowledgments}

The authors would like to thank Donghua University, and Jiaxing University. Also, many thanks for the supporting of the project of Scientific research project of Zhejiang Education Department (00717030AW) , the project of Special subject for reform and innovation of Talent Cultivation Mode of JiaXing University, the project of Cultural research project of Zhejiang Provincial Department of Culture (ZW2018045) and the project of Civil affairs policy theory research of Zhejiang Civil Affairs Bureau (ZMJF201810). Meanwhile, thanks to the editor and the readers of Asian Social Science.

\section{References}

Brucks, Zeithaml, V. A., \& Naylor, G.(2000). Price and brand name as indicators of quality dimensions for consumer durable. Academy of Marketing Science, 28(3), 359-374.

Cang, P., \& Cai, W. (2008). The Empirical Study on the Model of Fashion Marketing Strategy and the Comprise of Brand Equity. Journal of Donghua University (Natural Science), 32(4), 496-500. http://doi:10.3969/j.issn.1671-0444.2008.04.024

Ge, X. (2005). The Chinese consumers' changing value system, consumption value and modern consumption behavior. A Dissertation Submitted to the Graduate Faculty of Auburn University.

Glaser, B., \& Strauss, A. (1967). The discovery of grounded theory: Strategies for qualitative research. New York: Aldine De Gmyter.

Hammersley, M. (1989). The dilemma of qualitative method: Herbert blumer and the Chicago tradition (p. 105). London and New York.

Jilian, S. C., \& Soutar. (2001). Customer perceived value: the development to a multiple item scale. Journal of Retailing, 77(2), 203-220.

Monroe, S., Kent, B., \& Krishman, R. (1985). The effect of price comparison advertising on buyers' perceptions of acquisition value, transaction value, and behavioral intention. Journal of Marketing, 62(2), 46-59.

Parasueaman, A. (2000). Reflections on gaining competitive advantage trough customer value. Journal of the Academy Of Marketing Science, 25(2). 
Parasuraman, A., Zeithaml, V. A., \& Malhotra, A. (2005). E-S-Quail: a multiple-item scale for assessing electronic service quality. Journal of Service Research, 7(3), 213-233.

Petrick, J. F. (2002). Development of a mufti-dimensional sale for measuring the perceived value of a service. Journal of Leisure Research, 34(2), 119-134.

Schmitt, B., \& Alex, S. (1997). Marketing aesthetics: the strategic management of brands, identity and image (pp. 101-107). New York: The Free Press.

Sheth, J., Newman, B., \& Gross, B. (1991). Consumption values and market choices-theory and applications (pp. 188-192). Cincinnati: South-Western.

Strader, T. J., \& Shaw, M. J. (1997). Characteristics of electronic markets. Decision Support Systems, (21), 185-198.

Xiaochuan, J. (2003). Discussion on consciousness risk and marketing countermeasures of consumers. Journal of Chongqing Technology and Business University (Social Science Edition), 20(2), 74-76. http://dx.doi:10.3969/j.issn.1672-0598.2003.02.022

Xiaoyan, Y., \& Gujin, Z. (2006). Green Value: A New Dimension of Customer Perceived Values. China Industrial Economics, (7), 110-116. http://dx.doi:10.3969/j.issn.1006-480X.2006.07.015

Xiucheng, F. (2003). Study on Competitiveness of Service Firms: A Customer Perceived Value Perspective. Nankai Business Review, (6), 41-45. http://dx.doi:10.3969/j.issn.1008-3448.2003.06.009

\section{Copyrights}

Copyright for this article is retained by the author(s), with first publication rights granted to the journal.

This is an open-access article distributed under the terms and conditions of the Creative Commons Attribution license (http://creativecommons.org/licenses/by/4.0/). 